\title{
SISTEM TATANIAGA TANDAN BUAH SEGAR DI KECAMATAN WAMPU, KABUPATEN LANGKAT, SUMATERA UTARA
}

\author{
Fajar Rezeki Ananda Lubis* \\ Netti Tinaprilla** \\ *Alumnus Universitas Institut Pertanian Bogor \\ **Dosen Departemen Agribisnis Fakultas Ekonomi IPB \\ Email: fajarrezekiananda@gmail.com
}

\begin{abstract}
ABSTRAK
Kelapa sawit merupakan salah satu komoditas perkebunan yang dijadikan sebagai komoditas unggulan di Kecamatan Wampu, Kabupaten Langkat, Provinsi Sumatera Utara. Terdapat perbedaan yang cukup besar pada harga yang ditawarkan di tingkat petani dengan harga yang ditawarkan di tingkat konsumen. Tujuan penelitian ini adalah untuk mengidentifikasi saluran tataniaga dan efisiensi saluran tataniaga tandan buah segar (TBS) kelapa sawit yang terbentuk. Penentuan responden petani dilakukan secara purposive sampling sebanyak 30 orang dan responden lembaga tataniaga menggunakan metode snowball sampling. Hasil penelitian menunjukkan bahwa terdapat tiga saluran tataniaga TBS kelapa sawit yang terbentuk. Secara umum, sistem tataniaga TBS yang terbentuk tersebut belum efisien. Saluran yang paling banyak digunakan oleh petani adalah saluran I (petani-agen kecil-Agen besar-pabrik kelapa sawit) yang memiliki nilai marjin yang tinggi serta farmer's share yang rendah.
\end{abstract}

\section{Kata kunci: TBS, Saluran Tataniaga, Efisiensi Tataniaga}

\begin{abstract}
Oil Palm is the main plantation commodity in Wampu Subdistrict, Langkat Regency, North Sumatera. Products of oil palm plantations is the fruit of the palm-shaped bunches (FFB). There is a large gap of FFB price between market at the farm gate and consumer. The purpose of this study is to identify the marketing channel and the efficiency of FFB marketing channels. The method was used to select the respondents was purposive sampling with total result are 30 farmers and to select the marketing institutions was snowball sampling. The results showed that there are three channels formed. In general, all of the marketing channels of FFB had not been efficient. The major marketing channel is farmers - small retailers - large retailer - oil palm industry which has high margin and low farmer's share.
\end{abstract}

\section{Keyword : Oil Palm Fresh Fruit Bunch, Marketing Channel, Marketing Efficiency}

\section{PENDAHULUAN}

Komoditas perkebunan merupakan salah satu andalan bagi pendapatan nasional dan devisa negara Indonesia bila dibandingkan dengan sumbangan dari subsektor yang lainnya, subsektor perkebunan juga mengalami perkembangan yang sangat signifikan yang dapat dilihat dari kontribusinya terhadap perekonomian nasional. Pada 
tahun 2013 kontribusi subsektor perkebunan mencapai US\$ 45.54 milyar atau setara dengan Rp.637.56 trilliun (asumsi 1 US\$ = Rp. 14.000,-) yang meliputi ekspor komoditas perkebunan sebesar US\$ 35.64 milyar, cukai hasil tembakau US\$ 8.63 millyar dan bea keluar (BK) CPO dan biji kakao sebesar US\$ 1.26 milyar. Jika dibandingkan dengan tahun 2012 kontibusi subsektor perkebunan mengalami peningkatan sebesar $27.78 \%$ atau naik sebesar US49.90 milyar (Ditjenbun, 2015).

Peran subsektor perkebunan dalam pembangunan ekonomi nasional diperkuat dengan peningkatan luas areal dan produksi. Data pada Tabel 1 menunjukkan bahwa pertumbuhan areal perkebunan di Indonesia meningkat setiap tahun dalam rentang tahun 20092015. Komoditi yang mengalami pertumbuhan yang signifikan dalam periode tersebut adalah karet, kelapa sawit, dan kopi. jika dibandingkan dengan komoditas perkebunan lainnya dan komoditas kelapa sawit terus mengalami peningkatan dari tahun 2009 - 2015 dengan rata-rata pertumbuhan yaitu 7,14 persen.

Selain luas areal yang mengalami peningkatan, produksi perkebunan rakyat juga mengalami kenaikan dalam periode 2009 - 2015. Komoditi perkebunan yang mengalami peningkatan produksi paling signifikan adalah karet dan kelapa sawit.

Produksi kelapa sawit ditujukan untuk memenuhi permintaan pasar akan produk olahan kelapa sawit. TBS diolah di unit ekstraksi yang berlokasi di perkebunan menjadi produk setengah jadi yang berbentuk minyak kelapa sawit (MKS = Crude Palm Oil, CPO) dan inti kelapa sawit (IKS = Palm Kernel, PK). MKS dan IKS yang merupakan bahan setengah jadi memiliki permintaan yang cukup besar. MKS dan IKS dapat diolah menjadi bermacam-macam produk lanjutan dengan bermacam-macam kegunaan. Nilai tambah yang didapatkan sepanjang value chain agribisnis kelapa sawit didapat dari konversi bahan baku (sumberdaya alam) menjadi bahan baku proses (TBS), bahan setengah jadi (CPO dan PK) dan bahan jadi (produk akhir, baik edible mau nonedible). (Pahan, 2011)

Provinsi Sumatera Utara merupakan wilayah yang memiliki areal perkebunan yang luas dan potensial sebagai devisa bagi nasional dan pemerintah daerah setempat. Areal pengembangan perkebunan kelapa sawit dapat meliputi : perkebunan rakyat (swadaya), PBSA (Perkebunan Besar Swasta Asing), PBSN (perkebunan Besar Swasta Negara), dan pengembangan melalui pola PIR. Secara umum pengusahaan areal kelapa sawit di Sumatera Utara masih didominasi oleh perkebunan rakyat, sehingga pembangunan perkebunan ditempuh dengan Pendekatan perkebunan rakyat sebagai tulang punggung, sedangkan perusahaan perkenunan Negara dan sawasta sebagai pendukung.

Kabupaten Langkat merupakan salah satu sentra wilayah produksi TBS kelapa sawit kedua terbesar di Provinsi Sumatera Utara setelah Kabupaten Asahan. Luas areal yang ditanami kelapa sawit pada tahun 2014 adalah 46291.00 Ha, produksinya mencapai 146521.00 ton.

Perkebunan kelapa sawit di Kabupaten Langkat meliputi seluruh wilayah kecamatan yang ada, yaitu 19 kecamatan. Luas area dan produksi kelapa sawit di Kabupaten Langkat berdasarkan kecamatan. Pada Kabupaten Langkat terdapat empat kecamatan yang memiliki hasil produksi yang melebihi 60 000 ton TBS yaitu Kecamatan Batang Serangan, Selesai, Wampu dan Salapian. Produksi kelapa sawit dari kecamatan tersebut akan berkontribusi untuk memenuhi permintaan dari pabrik kelapa sawit. Sesuai dengan lokasi penelitian di Kecamatan Wampu, pada Tabel 6 menunjukan luas areal perkebunan kelapa sawit di Kecamatan 
Wampu seluas $3680 \mathrm{Ha}$ dengan total produksi 62424.00 Ton TBS.

Kecamatan Wampu merupakan salah satu daerah yang menjadikan kelapa sawit sebagai komoditas unggulan daerah dan menempati posisi ketiga dalam produksi TBS di Kabupaten Langkat. Potensi tersebut harus diimbangi dengan kesejahteraan pelaku utama usahatani tersebut, yaitu petani. Namun pada kenyataannya petani kelapa sawit di Kecamatan Wampu menerima harga yang rendah,

Sistem tataniaga tandan buah kelapa sawit di Kecamatan Wampu memegang peranan dalam upaya meningkatkan nilai tambah komoditas tersebut dan mempermudah pabrik kelapa sawit (PKS) dalam memenuhi pasokan bahan baku. Peningkatan produksi tanpa diiringi dengan pengembangan sistem tataniaga yang baik dapat menyebabkan harga menjadi rendah. Hal ini dapat berdampak pada perilaku petani dalam menjalankan usahataninya. Oleh karena itu, penting untuk mengkaji sistem tataniaga tandan buah kelapa sawit di Kecamatan Wampu agar dapat meningkatkan kesejahteraan petani.

Berdasarkan masalah-masalah yang ada di Kecamatan Wampu, Kabupaten Langkat terkait tataniaga tandan buah sawit, maka yang menarik untuk dikaji adalah sebagai berikut bagaimana sistem tataniaga TBS kelapa sawit di Kecamatan Wampu, Kabupaten Langkat dan manakah saluran tataniaga yang paling efisien di Kecamatan Wampu, Kabupaten Langkat dengan pendekatan marjin tataniaga, farmer's share, dan rasio biaya dan keuntungan

\section{METODE PENELITIAN}

Penelitian ini dilakukan di Kecamatan Wampu, Kabupaten Langkat, Sumatera Utara. Pemilihan lokasi ini dilakukan secara purposive sampling dengan pertimbangan bahwa Kecamatan Wampu merupakan salah satu sentra penghasil Kelapa Sawit di Kabupaten Langkat. Data yang digunakan dalam penelitian ini adalah data primer dan data sekunder. Data primer diperoleh melalui pengamatan secara langsung (observasi), wawancara dengan menggunakan daftar pertanyaan (kuisioner) kepada pelaku saluran tataniaga. Pengamatan secara langsung juga dilakukan terhadap kegiatan pemasaran kelapa sawit yang terjadi dan penelusuran saluran pemasaran dan lembaga-lembaga yang terlibat dalam saluran pemasaran kelapa sawit.

Data sekunder diperoleh dari studi literatur, tinjauan pustaka dan beberapa penelitian terdahulu. Selain itu data sekunder yang berhubungan data produksi, luas areal, produktivitas dan data tentang Kelapa Sawit didapat dari Departemen Pertanian, Direktorat Jenderal perkebunan, Dinas Perkebunan Sumatera Utara, KPB (Kantor Pemasaran Bersama). Data sekunder dipergunakan sebagai pelengkap data primer yang bersumber dari literatur. Pemilihan responden dilakukan dengan metode pengambilan contoh secara sengaja (purposive). Karakteristik petani dilihat dari jenis komoditi yang ditanam yaitu kelapa sawit, kondisi lahan dan pemukimannya jauh dari jalan utama desa dan jauh dari PKS, dan petani yang pernah melakukan pemanenan kelapa sawit. Responden pedagang yang diwawancarai dipilih berdasarkan alur pemasaran TBS. Pengambilan sampel dilakukan dengan snowball sampling yaitu dengan cara mengikuti alur pemasaran mulai dari produsen (petani) hingga konsumen akhir dan menelusuri saluran pemasaran di daerah penelitian berdasarkan informasi yang didapat dari pelaku pasar yaitu mulai dari tingkat petani sampai PKS. Hal ini untuk menghindari lembaga pemasaran yang dianalisis efisiensi pemasarannya ternyata tidak menggunakan saluran pemasaran yang telah terbentuk sebelumnya. Jumlah responden petani adalah sebanyak 30 orang. Sedangkan jumlah pedagang responden sebanyak 6 orang yang terdiri dari empat agen 
kecil, dan dua Agen besar.

Analisis margin tataniaga bertujuan untuk mengetahi tingkat efisiensi dari pemasran tandan buah segar di Kecamatan Wampu. Selain itu, margin tataniaga digunakan untuk perbedaan pendapatan yang diterima oleh masingmasing lembaga. Besarnya margin merupakan penjumlahan dari biayabiaya pemasaran yang dikeluarkan dan keuntungan yang diperoleh

$\mathrm{Mi}=\mathrm{Psi}-\mathrm{Pbi}$

Keterangan :

$\mathrm{Mi}=$ margin tataniga tingkat ke- $\mathrm{i}$

Psi = harga jual pasar di tingkat ke-

i Pbi = harga beli pasar di tingkat ke i

Margin tataniaga juga dapa diperoleh dari penjumlahan biaya dan keuntungan pada masing-masing lembaga tataniaga. Secara sistematis dapat dirumuskan sebagai berikut :

$\mathrm{Mi}=\mathrm{Ci}+\pi \mathrm{i}$

Keterangan :

$\mathrm{Ci}=$ biaya lembaga tataniaga di

tingkat ke-i

$\pi \mathrm{i}=$ Keuntungan lembaga tataniag di

tingkat ke-i

Dari persamaan (1) dan (2), maka diperoleh persamaan sebagai berikut:

$\mathrm{Psi}-\mathrm{Pbi}=\mathrm{Ci}+\pi \mathrm{i}$

Dengan demikian keuntungan lembaga tataniaga di tingkat ke-I sebesar :

$\pi \mathrm{i}=\mathrm{Psi}-\mathrm{Pbi}-\mathrm{Ci}$

(Asmarantaka, 2012)

\section{Analisis Rasio Keuntungan dan Biaya}

Rasio keuntungan dan biaya (Analisis $\mathrm{R} / \mathrm{C}$ Ratio) adalah persentase keuntungan pemasaran terhadap biaya pemasaran yang secara teknis (Operasional) untuk mengetahui tingkat efisiensinya. Penyebaran rasio keuntungan dan biaya pada masing- masing lembaga pemasaran dapat dirumuskan sebagai berikut:

Rasio Keuntungan Biaya; $\pi=L i / C i$

Keterangan:

Li : Keuntungan Lembaga

Pemasaran

$\mathrm{Ci}$ : Biaya Pemasaran

\section{Analisis Farmer's Share}

Pendapatan yang diterima petani (farmer's share) merupakan perbandingan persentase harga yang diterima oleh petani dengan harga yang dibayar di tingkat konsumen akhir. Secara matematis farmer's share dihitung sebagai berikut:

$$
F s i=\frac{P f}{P r} \times 100 \%
$$

Keterangan:

Fsi : Persentase Yang Diterima

Petani Pf : Harga di Tingkat Petani

Pr : Harga di Tingkat Konsumen

Semakin mahal konsumen membayar harga yang ditawarkan oleh lembaga pemasaran (pedagang), maka yang diterima oleh petani akan semakin sedikit, karena petani menjual komoditi pertanian dengan harga yang relatif rendah. Hal ini memperlihatkan adanya hubungan negatif antara marjin pemasaran dengan bagian yang diterima oleh petani. Semakin besar marjin pemasaran maka penerimaan petani relatif kecil.

\section{HASIL DAN PEMBAHASAN}

Lembaga Tataniaga

Saluran tataniaga tandan buah sawit dari petani hingga ke konsumen melibatkan beberapa lembaga tataniaga. Berikut ini lembaga tataniaga yang terlibat dalam tataniaga tandan buah sawit.

1. Petani yang berjumlah 30 responden merupakan lembaga yang berperan dalam memproduksi TBS dengan total produksi 17 
850,48 ton/tahun dengan produktivitas 16,16 ton/ha/tahun.

2. Agen kecil yang terdiri dari empat responden merupakan pembeli TBS yang kemudian menyalurkan TBS kepada agen besar.

3. Agen besar yang terdiri dari dua responden dan memiliki badan hokum yaitu UD. Lancar Sawit dan PT. Risky Fajar Adiputra merupakan pembeli TBS dari petani dan perantara setelah agen kecil yang menyalurkan TBS dalam skala besar kepada Pabrik Kelapa Sawit (PKS).

Pabrik Kelapa Sawit (PKS) yang terdiri dari dua responden dan memiliki badan hukum yaitu dari pihak swasta PT. XYZ dan dari pihak BUMN PT. ABC merupakan konsumen akhir dari TBS.

Saluran Tataniaga

Saluran tataniaga tandan buah kelapa sawit yang terdapat di Kecamatan Wampu Kabupaten Langkat ada tiga saluran, yaitu:

1) Petani - Agen Kecil - Agen Besar - PKS

2) Petani - Agen Besar - PKS

3) Petani - PKS.

Saluran tataniaga TBS di Kecamatan Wampu, Kabupaten Langkat dapat dilihat pada

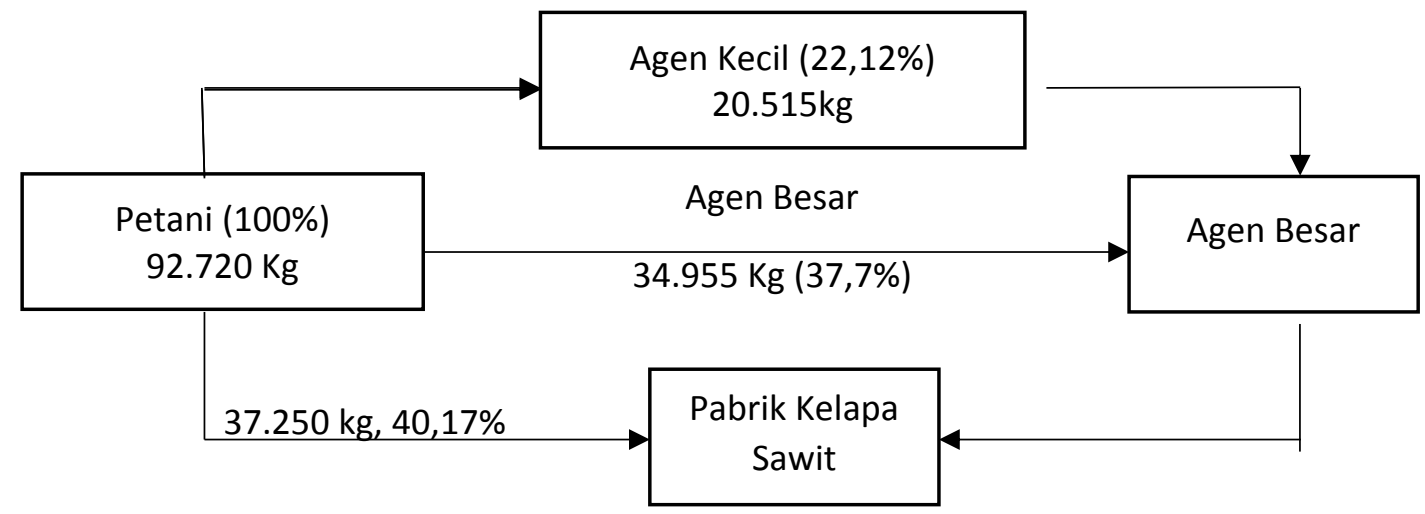

\section{Gambar 1. Saluran tataniaga Tandan Buah Sawit}

\section{Saluran tataniaga I}

Saluran tataniaga I terdiri dari petani, agen kecil, agen besar, dan pabrik kelapa sawit. Jumlah petani responden yang melakukan saluran tataniaga satu adalah lima belas orang atau sebesar 50 persen. Volume penjualan TBS pada saluran ini sebesar $20515 \mathrm{Kg}$ atau 22.12 persen dari total volume penjualan TBS dengan produktivitas $14624 \mathrm{Kg} / \mathrm{Ha} /$ tahun.

Petani melakukan saluran tataniaga ini karena petani tidak mempunyai alternatif lain dalam menyalurkan TBSnya. Hal yang mendasari petani menjual kepada agen kecil ialah luas lahan perkebunan yang kecil dan jarak lahan perkebunan yang jauh dari PKS dan tempat pedagang besar. TBS petani dibeli oleh agen kecil dengan harga rata-

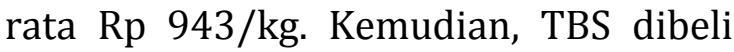
agen besar dengan harga Rp 1 067,5/kg. Selanjutnya, agen besar ini akan mengirimkan TBS ke Pabrik Kelapa Sawit biasanya membeli buah dengan kisaran harga Rp 1 275-1 325 per kg. Hasil pengolahan TBS ini biasanya akan langsung dikirim oleh pabrik kelapa sawit ke pelabuhan Belawan dan selanjutnya diekspor ke luar negeri.

Pada saluran satu, harga tandan buah kelapa sawit ditentukan oleh Pabrik kelapa Sawit, dalam hal ini PKS Swasta PT, XYZ. Berdasarkan harga yang ditentukan oleh KPB (Kantor Pemasaran Bersama) mengacu pada harga CPO dunia. Sistem pembelian yang dilakukan oleh lembaga tataniaga kepada petani adalah dengan sistem timbang dan 
dibayar secara tunai. Agen kecil akan menjualnya pada agen buah yang besar dan pada akhirnya Agen besar ini akan menjualnya kepada Pabrik Kelapa Sawit dengan sistem pembayaran hutang 1 minggu. Dengan demikian, pada saluran ini petani mengeluarkan biaya tataniaga seperti biaya pemanenan. Sedangkan, agen mengeluarkan biaya bongkar muat dan biaya pengangkutan.

\section{Saluran Tataniaga II}

Saluran tataniaga II dilakukan oleh tiga belas petani responden, saluran ini terdiri dari petani, agen besar dan PKS. Para petani yang melakukan saluran tataniga ini dikarenakan mereka mempunyai kedekatan dengan pedagang besar dan akses lahan perkebunan yang dekat dengan lokasi tempat penyimpanan dan akses jalan yang mudah dimasuki sehingga memudahkan para agen untuk masuk. Agen besar pada saluran ini ingin mendapatkan profit yang lebih tinggi sehingga memotong fungsi agen kecil yaitu dengan mencari petani sendiri dengan kriteria lahan yang luas untuk mendapatkan produksi yang stabil. Volume penjualan tandan buah kelapa sawit pada saluran ini sebesar 34 $955 \mathrm{Kg}$ per panen atau sebesar 37,70 persen dari total volume penjualan tandan buah kelapa sawit dengan produktivitas $17419 \mathrm{Kg} / \mathrm{Ha} / \mathrm{Tahun}$.

Agen besar akan mendatangi petani yang sedang memanen kelapa sawit. Kemudian, tandan buah kelapa sawit yang telah dipanen akan ditimbang dan dimasukkan ke dalam truk pengangkut. Harga beli rata-rata TBS adalah Rp 955/kg. Setelah mengumpulkan TBS, agen buah akan mengangkut buah sawit tersebut langsung ke Pabrik Kelapa Sawit (PKS) dalam hal ini PKS BUMN PT. ABC dan PKS swasta XYZ membeli buah dengan harga rata-rata Rp. 1312,5 per kg. Pada saluran ini para petani mengeluarkan biaya pemanenan karena petani pada saluran ini menggunakan BHL (Buruh Harian Lepas). Agen buah mengeluarkan biaya transportasi (pengangkutan), biaya bongkar muat TBS, retribusi dan tenaga kerja pencari petani. Pabrik kelapa sawit XYZ mengeluarkan biaya pengolahan pabrik untuk mengolah TBS menjadi CPO (Crude Palm Oil) dan PKO (Palm kernel Oil).

\section{Saluran Tataniaga III}

Saluran ketiga terdiri dari petani dan PKS, jumlah responden pada saluran ini hanya dua petani. Petani pada saluran ketiga ini langsung menjual hasil panen tandan buah sawit kepada Pabrik Kelapa Sawit. Para petani pada saluran ketiga ini mempunyai angkutan sendiri untuk mengangkut hasil panen TBS langsung ke pabrik kelapa sawit. Selain mempunyai alat angkut TBS, mereka juga mempunyai lahan kelapa sawit yang luas dan izin untuk menjadi pemasok TBS di PKS, yaitu ABC Langkat dan PKS XYZ. Petani ini juga bertindak sebagai pedagang besar atau agen TBS untuk memasok ke PKS. Volume penjualannya yang mencapai $37250 \mathrm{Kg}$ atau 40,17 persen dari total penjualan dengan produktivitas $14571,43 \mathrm{Kg} / \mathrm{Ha} / \mathrm{Tahun}$.

Petani pada saluran ini yang telah memanen TBS mengeluarkan biaya pemanenan kemudian, biaya pengangkutan. Hasil panen tersebut dikumpulkan dan langsung diangkut ke pabrik kelapa sawit. Pabrik kelapa sawit akan menyortir TBS sebelum dimasukkan ke dalam loading ramp untuk diolah menjadi CPO (Crude Palm Oil) dan PKO (Palm Kernel Oil). Hasil pengolahan yang berupa CPO ini akan langsung diekspor ke luar negeri melalui pelabuhan Belawan.

Harga tandan buah kelapa sawit ini biasa dibeli oleh PKS dengan kisaran Rp 1275 - Rp.1 325 per kg. Harga ini ditentukan per harinya oleh pabrik berdasarkan perhitungan dan memakai harga CPO dunia. Harga CPO dunia sangat berfluktuaktif sehingga menyebabkan harga tandan buah kelapa sawit berubah- ubah setiap harinya. 
Fungsi - fungsi tataniaga yang dilakukan semua lembaga tataniaga yang telah diuraikan tersebut dapat dilihat pada Tabel 1.

Tabel 1. Fungsi-fungsi tataniaga yang dilakukan lembaga tataniaga TBS di Kecamatan Wampu, Kabupaten Langkat

\begin{tabular}{|c|c|c|c|c|c|}
\hline \multirow{2}{*}{\multicolumn{2}{|c|}{ Fungsi Tataniaga }} & \multicolumn{4}{|c|}{ Lembaga Tataniaga } \\
\hline & & \multirow{2}{*}{$\frac{\text { Petani }}{-}$} & \multirow{2}{*}{$\begin{array}{c}\text { Agen Kecil } \\
\checkmark\end{array}$} & \multirow{2}{*}{$\begin{array}{c}\text { Agen Besar } \\
\checkmark\end{array}$} & \multirow{2}{*}{$\begin{array}{c}\text { Pabrik } \\
\text { Kelapa Sawi } \\
\checkmark\end{array}$} \\
\hline Fungsi & Beli & & & & \\
\hline \multirow{2}{*}{ Pertukaran } & Jual & $\checkmark$ & $\checkmark$ & $\checkmark$ & $\checkmark$ \\
\hline & Pengolahan & - & - & - & $\checkmark$ \\
\hline \multirow[t]{3}{*}{ Fungsi Fisik } & Pengangkutan & $\checkmark$ & $\checkmark$ & $\checkmark$ & $\checkmark$ \\
\hline & Sortasi & - & - & $\checkmark$ & $\checkmark$ \\
\hline & Penyimpanan & - & - & $\checkmark$ & $\checkmark$ \\
\hline \multirow{3}{*}{$\begin{array}{c}\text { Fungsi } \\
\text { Fasilitas }\end{array}$} & Biaya & - & $\checkmark$ & $\checkmark$ & $\checkmark$ \\
\hline & Resiko & - & - & - & - \\
\hline & $\begin{array}{l}\text { Informasi } \\
\text { Pasar }\end{array}$ & - & $\checkmark$ & $\checkmark$ & $\checkmark$ \\
\hline
\end{tabular}

\section{Analisis Margin Tataniaga}

Margin tataniaga merupakan selisih harga jual dan harga beli di tingkat petani dan di tingkat pedagang pada lembaga tataniaga. Margin tataniaga meliputi biaya tataniaga yang dikeluarkan dalam setiap lembaga tataniaga dan keuntungan yang didapat oleh lembaga tataniaga dalam menyalurkan produk pertanian dari produsen hingga ke tangan konsumen. Dalam penelitian kali ini, margin tataniaga yang akan dihitung menggunakan prinsip kesetaraan. Semua satuan dalam perhitungan margin tataniaga tandan buah kelapa sawit ini adalah Rupiah per kg TBS. Perhitungan yang digunakan adalah rendemen TBS petani sebesar 21 persen. Rendemen 21 persen berarti bahwa satu ton TBS menghasilkan 210 kilogram CPO (Crude Palm Oil). Rendemen untuk PKO (Palm Kernel Oil) TBS petani adalah lima persen, artinya untuk setiap 1 ton TBS akan menghasilkan 50 kilogram
PKO.

Pada saluran tataniaga I, petani mengeluarkan biaya tataniaga yang terdiri dari biaya pemanenan Rp. 200/kg TBS. Biaya ini dikategorikan mahal dibanding dengan saluran lainnya yang disebabkan oleh kuantitas TBS yang dipanen sedikit dan siklus panen yang hanya dilakukan setiap minggu. Agen kecil pada saluran ini mengeluarkan biaya pengangkutan rata-rata Rp. $35 / \mathrm{kg}$. Kemudian biaya yang dikeluarkan oleh agen kecil adalah biaya bongkar muat yaitu Rp. 10/kg TBS. Total biaya yang dikeluarkan agen kecil adalah Rp $33.2 / \mathrm{kg}$. Agen besar yang terlibat pada saluran tataniaga I ini mengeluarkan biaya pengangkutan $\mathrm{Rp} .77 / \mathrm{Kg}$, biaya bongkar Rp. $25 / \mathrm{Kg}$, Biaya muat Rp. 25/Kg dan retribusi sebesar Rp. 20/Kg Total biaya yang dikeluarkan agen besar adalah Rp. 147/Kg. Berikut adalah Tabel 10 biaya tataniaga yang dikeluarkan lembaga tataniaga pada saluran tataniaga I. 
Tabel 3. Biaya tataniaga yang dikeluarkan setiap lembaga tataniaga pada saluran tataniaga I

\begin{tabular}{lc}
\hline \multicolumn{1}{c}{ Jenis Biaya } & Rata-Rata (Rupiah per Kilogram) \\
\hline Petani & \\
Biaya Pemanenan & 200 \\
Total & 200 \\
\hline Agen kecil & \\
Biaya Bongkar Muat & 10 \\
Biaya Pengangkutan & 26 \\
Total & 36 \\
\hline Agen besar & \\
Biaya Pengangkutan & 77 \\
Biaya Bongkar dan Muat & 50 \\
Biaya Retribusi & 20 \\
Total & 147 \\
\hline
\end{tabular}

Pada saluran tataniaga yang II para petani langsung didatangi oleh tenaga kerja agen besar. Hal ini dilakukan oleh agen besar untuk mendapatkan margin yang lebih banyak. Pada umumnya setiap petani yang menjual kepada agen besar adalah langganan sudah lama, berada di sekitar tempat pangkalan penyimpanan TBS agen besar dan terdapat satu responden memiliki ikatan keluarga dengan agen besar.

Tabel 4. Biaya tataniaga yang dikeluarkan lembaga tataniaga pada saluran tataniaga II Jenis Biaya Rata-rata (Rupiah/Kilogram)

\begin{tabular}{lc}
\hline Petani & 28 \\
Biaya Pemanenan & 28 \\
Total & \\
\hline Agen besar & 76,5 \\
Biaya Pengangkutan & 50 \\
Biaya Bongkar dan muat & 20 \\
Biaya Retribusi & \\
Agen besar & 72,5 \\
Biaya Tenaga kerja & 219 \\
Total & \\
\hline
\end{tabular}

Biaya yang dikeluarkan oleh petani adalah biaya pemanenan rata-rata Rp. 28/kg TBS. Biaya yang dikeluarkan oleh agen besar untuk pengangkutan sebesar $76,5 / \mathrm{kg}$, biaya biaya bongkar muat adalah $50 / \mathrm{kg}$, biaya retribusi $\mathrm{Rp}$. $20 / \mathrm{Kg}$, dan biaya tenaga kerja dalam hal ini pemasaran yang khusus mencari petani sebesar Rp. 72,5/Kg. Total biaya yang dikeluarkan agen buah adalah Rp. $219 / \mathrm{Kg}$. Berikut adalah tabel total biaya yang dikeluarkan oleh lembaga tataniaga pada saluran tataniaga II.

Pada saluran tataniaga yang III petani langsung mengirimkan TBS ke pabrik kelapa sawit. Biaya yang dikeluarkan oleh petani adalah biaya pemanenan Rp. 28/kg TBS. Biaya pengangkutan yang dikeluarkan petani adalah rata-rata $74 / \mathrm{kg}$ TBS. Biaya bongkar muat adalah $50 / \mathrm{kg}$ TBS. Total biaya yang dikeluarkan para petani adalah Rp. 124/kg TBS. Berikut adalah tabel total biaya yang dikeluarkan oleh petani pada saluran tataniaga III. 
Tabel 5. Biaya tataniaga yang dikeluarkan lembaga tataniaga pada saluran tataniaga III

\begin{tabular}{lr}
\hline \multicolumn{1}{c}{ Jenis Biaya } & Rata-rata (Rupiah/Kilogram) \\
\hline Petani & \\
Biaya Pemanenan & 27.25 \\
Biaya Pengangkutan & 72,5 \\
Biaya Bongkar muat & 50 \\
Total & 149,75 \\
\hline
\end{tabular}

Margin di setiap saluran tataniaga berbeda-beda karena perbedaan biaya pemasaran yang dikeluarkan dan keuntungan yang diperoleh untuk setiap lembaga tataniaga. Nilai margin tataniaga yang kecil menunjukkan bahwa saluran tataniaga tersebut efisien karena perbedaan harga jual di tingkat petani dan harga beli di lembaga tataniaga akhir kecil hal ini akan menguntungkan petani. Nilai margin tataniaga yang besar menunjukkan bahwa saluran tataniaga tersebut tidak efisien karena perbedaan harga jual di tingkat petani dan harga beli di tingkat lembaga tataniaga terakhir besar hal ini akan merugikan petani.

Berdasarkan analisis margin tataniaga TBS dapat pada Tabel 13 dapat dilihat bahwa saluran tataniaga pertama memiliki marjin tataniaga dengan nilai yang paling besar. Hal ini disebabkan pada saluran tataniaga I merupakan saluran terpanjang dengan melalui beberapa lembaga tataniaga sebelum mencapai pabrik kelapa sawit.
Jika dihubungkan kepada fungsi tataniaga, biaya transportasi yang menjadi biaya yang cukup besar pada saluran ini. Kemudian jika dihubungkan kepada perilaku pasar pada saluran tataniaga I ini setiap lembaga sudah menjalani kerjasama yang terjalin sejak lama, tidak mungkin untuk keluar dari pasar ini jika dihubungkan dengan struktur pasar. Pada saluran tataniaga III memiliki nilai marjin tataniaga paling kecil. Hal ini disebabkan petani pada saluran tataniaga III ini memliki alat pengangkutan sendiri untuk menjual tandan buah sawit kepada Pabrik Kelapa Sawit. Rincian mengenai margin tataniaga dan keuntungan yang diterima oleh setiap lembaga tataniaga setelah biaya tataniaga yang dikeluarkan agen buah ditambahkan dengan keuntungan yang mereka ambil. Margin tataniaga dan keuntungan yang diterima setiap lembaga tataniaga berdasarkan pendapatan petani yang berasal dari harga TBS dapat dilihat pada Tabel 4. 
Tabel 6. Marjin Tataniaga TBS setiap saluran tataniaga di Kecamatan Wampu, Kabupaten Langkat

\begin{tabular}{|c|c|c|c|}
\hline \multirow{3}{*}{ Uraian } & \multicolumn{3}{|c|}{ Saluran Tataniaga } \\
\hline & 1 & 2 & 3 \\
\hline & Nilai (Rp/Kg) & Nilai (Rp/Kg) & Nilai (Rp/Kg) \\
\hline \multicolumn{4}{|l|}{ Petani } \\
\hline Harga Jual & 943.00 & 955.00 & 1312.50 \\
\hline Biaya Tataniaga & 200.00 & 28.00 & 149.75 \\
\hline \multicolumn{4}{|l|}{ Agen kecil } \\
\hline Harga Jual & 1067.50 & & \\
\hline Harga Beli & 943.00 & & \\
\hline Biaya Tataniaga & 36.00 & & \\
\hline Keuntungan & 88.50 & & \\
\hline Margin & 124.50 & & \\
\hline \multicolumn{4}{|l|}{ Agen besar } \\
\hline Harga Jual & 1325.00 & 1312.5 & \\
\hline Harga Beli & 1067.00 & 955.00 & \\
\hline Biaya Tataniaga & 147.00 & 219.00 & \\
\hline Keuntungan & 110.00 & 138.00 & \\
\hline Margin & 257.50 & 357.50 & \\
\hline \multicolumn{4}{|l|}{ PKS } \\
\hline Harga Beli & 1325.00 & 1312.50 & 1312.50 \\
\hline Total Biaya & 383.00 & 247.00 & 149.75 \\
\hline Tataniaga & & & \\
\hline Total Keuntungan & 199.00 & 138.50 & - \\
\hline Total Margin & 382.00 & 357.50 & - \\
\hline
\end{tabular}

\section{Farmer's Share}

Farmer's share adalah selisih antara harga retail dan margin tataniaga. Hal ini digunakan untuk mengatahui porsi harga di tingkat konsumen yang dinikmati oleh petani. Melalui farmer's share dapat diketahui efisien atau tidaknya sebuah saluran tataniaga. Nilai farmer's share yang besar berarti porsi atau bagian yang dinikmati petani besar dan saluran tataniaga tersebut efisien. Nilai farmer's share yang kecil berarti porsi atau bagian yang dinikmati oleh petani kecil dan saluran tataniaga tersebut tidak efisien. Analisis farmer's share dari tataniaga TBS di Kecamatan Wampu, Kabupaten Langkat dapat dilihat pada Tabel $14 \mathrm{di}$ bawah ini.

Tabel 7. Analisis Farmer's share saluran tataniaga TBS di Kecamatan Wampu, Kabupaten Langkat tahun 2015

\begin{tabular}{cccc}
\hline $\begin{array}{c}\text { Saluran } \\
\text { Tataniag }\end{array}$ & $\begin{array}{c}\text { Harga di Tingkat } \\
\text { Petani }\end{array}$ & $\begin{array}{c}\text { Harga di Tingkat } \\
\text { Konsumen }\end{array}$ & $\begin{array}{c}\text { Farmer's } \\
\text { Share }(\%)\end{array}$ \\
\hline I & 943 & 1325 & 71,16 \\
II & 955 & 1312 & 72,78 \\
III & 1312 & 1312 & 100 \\
\hline
\end{tabular}

Farmer's share tertinggi terdapat pada saluran tataniaga III sebesar 100 persen, hal ini karena petani pada saluran ini menjual langsung ke PKS tanpa melalui pedagang perantara. Pada analisis margin tataniaga saluran tataniaga III tidak memiliki nilai margin tataniaga karena pada saluran tataniaga III ini petani mempunyai transportasi sendiri untuk langsung mengirim TBS 
langsung kepada pabrik kelapa sawit dan kerjasama kedua lembaga tataniaga ini sudah terjalin sejak lama. Nilai margin yang ada pada saluran lain terjadi karena adanya agen buah sawit. Hal ini memungkinkan terjadi apabila petani tersebut mempunyai mobil pengangkutan pribadi, dan sudah berbentuk badan hukum sehingga bisa memasukan hasil panen ke PKS karena pada umumnya PKS hanya bertransaksi dengan perusahaan bukan perorangan. Sedangkan farmer's share terkecil didapatkan oleh saluran tataniaga I sebesar 71,16 persen dan mendapatkan margin tataniaga terbesar sebesar 28,83 persen. Saluran tataniaga I ini merupakan saluran tataniaga yang terpanjang, karena pada saluran ini melibatkan agen kecil dan agen besar. Karena memiliki saluran tataniaga yang panjang, semakin kecil nilai yang keuntungan yang didapatkan petani dan semakin besar nilai marjin tataniaga. Jika dihubungkan dengan perilaku dan struktur pasar, kerjasama pada saluran tataniaga I sudah terjalin sejak lama dan sulit bagi para lembaga tataniaga untuk melepaskan diri dari pasar ini. Pengangkutan pada saluran tataniaga I ini memakan biaya yang cukup besar.

Jika dilihat dari analisis margin tataniaga dan farmer's share maka saluran tataniaga III dapat dikatakan paling efisien karena nilai margin saluran tataniaga III terkecil dan farmer's share yang didapatkan petani juga paling besar. Selain itu fungsi fisik yaitu pengangkutan pada saluran tataniaga III ini ditanggung oleh petani, tidak melibatkan agen buah sawit. Kemudian kerjasama antara pabrik kelapa sawit dan petani sudah terjalin sejak lama.

\section{Rasio Keuntungan Terhadap Biaya}

Rasio keuntungan terhadap biaya dapat digunakan untuk melihat efisiensi suatu sistem tataniaga. Rasio keuntungan dan biaya tataniaga mendefinisikan besarnya keuntungan yang diterima atas biaya tataniaga yang dikeluarkan. Nilai rasio keuntungan terhadap biaya lebih dari satu hal ini berarti saluran tersebut layak untuk dijalankan dan telah memberikan keuntungan kepada lembaga tataniaga yang terlibat didalamnya. Analisis rasio keuntungan dan biaya tataniaga TBS dapat dilihat pada Tabel 8 dibawah ini.

Tabel 8. Analisis rasio keuntungan terhadap biaya saluran tataniaga TBS di Kecamatan Wampu, Kabupaten Langkat

\begin{tabular}{lrrrr}
\hline \multicolumn{1}{c}{$\begin{array}{c}\text { Saluran } \\
\text { Tataniag }\end{array}$} & $\begin{array}{c}\text { Keuntungan } \\
\text { Tataniaga }\end{array}$ & $\begin{array}{c}\text { Biaya } \\
\text { Tataniaga }\end{array}$ & $\begin{array}{c}\text { Rasio } \\
\text { Keuntungan }\end{array}$ \\
\hline Saluran I & & & & \\
Petani & 743.00 & 200.00 & 3.71 \\
Agen kecil & 124.50 & 36.00 & 3.46 \\
Agen besar & 257.50 & 147.00 & 1.74 \\
Total & 1082.00 & 383.00 & 2.82 \\
\hline Saluran II & & & \\
Petani & 927.00 & 28.00 & 33.10 \\
Agen besar & 357.50 & 219.00 & 1.63 \\
Total & 1297.00 & 247.00 & 5.25 \\
\hline Saluran III & & & \\
Petani 1325 & 1163.00 & 149.75 & 7.76 \\
Total 124 & 1163.00 & 149.75 & 7.76 \\
\hline
\end{tabular}

Berdasarkan tabel di atas pada setiap saluran tataniaga memiliki nilai rasio keuntungan dan biaya lebih dari satu, hal ini berarti kegiatan tataniaga yang dilakukan oleh setiap lembaga tataniaga masing-masing memberikan keuntungan. Rasio keuntungan terhadap biaya pada saluran pertama adalah 2,82. Hal ini berarti setiap Rp. 
1/kg TBS akan menghasilkan keuntungan sebesar Rp. 2,82/kg TBS. Nilai rasio keuntungan terhadap biaya pada saluran tataniaga dua yaitu sebesar 5,25. Hal ini berarti setiap Rp. $1 / \mathrm{kg}$ TBS akan menghasilkan keuntungan sebesar Rp. 5,25/kg TBS. Rasio keuntungan terhadap biaya pada saluran ketiga sebesar 7,76. Setiap Rp. $1 / \mathrm{kg}$ TBS akan menghasilkan keuntungan sebesar Rp. 7,76/kg TBS.

Berdasarkan perhitungan rasio keuntungan terhadap biaya maka saluran tataniaga III yang relatif lebih efisien karena memiliki nilai rasio keuntungan terhadap biaya paling besar. Sedangkan saluran tataniaga I relatif tidak efisien karena memiliki nilai rasio keuntungan terhadap biaya yang paling kecil.

\section{Efisiensi Tataniaga}

Efisiensi tataniaga dapat tercapai apabila sistem tataniaga yang ada telah memberikan kepuasan kepada pelakupelaku yang terlibat, mulai dari petani hingga PKS. Berdasarkan hasil analisis tataniaga TBS di Kecamatan Wampu diperoleh nilai efisiensi tataniaga untuk masing-masing saluran tataniaga pada Tabel 16.

Ada beberapa faktor indikator untuk menentukan efisiensi saluran tataniaga TBS di Kecamatan Wampu, diantaranya dengan melihat nilai marjin tataniaga, farmer's share, sebaran nilai rasio keuntungan atas biaya pemasaran dan volume penjualan TBS. Jika dilihat dari keseluruhan fungsi yang dilakukan, saluran tataniaga III merupakan saluran yang lebih efisien. Saluran III memiliki farmer's share yang tertinggi dan harga yang ditawarkan di tingkat petani merupakan harga tertinggi di antara saluran yang lain. 
Tabel 9. Nilai efisiensi tataniaga pada masing-masing saluran tataniaga pada masingmasing saluran tataniaga TBS di Kecamatan Wampu

\begin{tabular}{|c|c|c|c|}
\hline \multirow{3}{*}{ Indikator } & \multicolumn{3}{|c|}{ Saluran Tataniaga } \\
\hline & I & II & III \\
\hline & & & $(n=2)$ \\
\hline $\begin{array}{l}\text { Total } \\
\text { Margin }\end{array}$ & 382.00 & 357.50 & 8 \\
\hline $\begin{array}{l}\text { Farmer's Share } \\
(\%)\end{array}$ & 71.16 & 72.78 & 100 \\
\hline Rasio $\pi \mathrm{i} / \mathrm{Ci}$ & 2.82 & 5.25 & 7.76 \\
\hline Volume (Kg) & 20515 & 34955 & 37250 \\
\hline $\begin{array}{l}\text { Harga di } \\
\text { tingkat Petani }\end{array}$ & 943.00 & 955.00 & 1312.50 \\
\hline
\end{tabular}

Keterangan : $\mathrm{n}$ : Jumlah Petani

\section{SIMPULAN}

Kesimpulan yang dapat diambil dari sistem tataniaga TBS di Kecamatan Wampu Kabupaten Langkat adalah sebagai berikut:Saluran tataniaga sawit yang terbentuk di Kecamatan Wampu, Kabupaten Langkat ada tiga saluran, yaitu: (1) Saluran tataniaga pertama, yaitu Petani - Agen kecil - Agen besar - Pabrik Kelapa Sawit, (2) Saluran tataniaga kedua, yaitu Petani - Agen besar - Pabrik Kelapa Sawit, (3) Saluran tataniaga ketiga, yaitu Petani - Pabrik Kelapa Sawit. Berdasarkan margin tataniaga, farmer's share, dan rasio keuntungan terhadap biaya menunjukkan saluran tataniaga III merupakan saluran yang paling efisien. Saluran tataniaga III adalah yang paling efisien karena memiliki farmer's share sebesar 100 persen dan tidak memiliki marjin tataniaga karena petani pada saluran tersebut menjual langsung kepada pabrik kelapa sawit tanpa melalui agen buah. Pada saluran tataniaga III melakukan volume penjualan terbesar. Volume penjualan pada saluran ketiga sebesar $37250 \mathrm{Kg}$ atau sebesar 40,17 persen.

\section{DAFTAR PUSTAKA}

Asmarantaka, Ratna W. 2009. Pemasaran Produk-Produk Pertanian dalam Bunga Rampai Agribisnis Seri Pemasaran. Editor Nunung Kusnadi,dkk. Bogor: IPB press.

Asmarantaka RW. 2012. Pemasaran Agribisnis (Agrimarketing). Bogor(ID): Departemen Agribisnis FEM-IPB

Asmarantaka Ratiza A. 2013. Analisa tataniaga kelapa sawit di Desa Tanjung Jaya Kecamatan Bangun Rejo Kabupaten Lampung Tengah Provinsi Lampung [skripsi]. Bogor (ID): Institut Pertanian Bogor

Badan Pusat Statistik. 2015 , Kabupaten Langkat Dalam Angka 2015. Medan : BPS

Badan Pusat Statistik. 2015 , Sumatera Utara Dalam Angka 2015. Medan : BPS Dewi A. 2014. Analisis tataniaga salak pondoh di Desa Wonokerto, Kecamatan

Turi, Kabupaten Sleman [Skripsi]. Bogor (ID): Institut Pertanian Bogor Direktorat Jenderal Perkebunan. 2016 . Luas Areal Tanaman 
Perkebunan di Indonesia. Jakarta : Ditjenbun

Direktorat Jenderal Perkebunan. 2016. Produksi Kelapa Sawit Berdasarkan Provinsi di Indonesia. Jakarta : Ditjenbun

Direktorat Jenderal Perkebunan. 2016 . Produksi Tanaman Perkebunan di Indonesia. Jakarta : Ditjenbun

Direktorat Jendral Perkebunan. 2015. Peranan Perkebunan dalam Perekonomian Nasional. Jakarta: Kementrian Pertanian

Fikri M. 2013. Sistem tataniaga tomat (kasus di Desa Tugumukti, Kecamatan Cisarua, Kabupaten Bandung Barat) [skripsi]. Bogor (ID): Institut Pertanian Bogor.

Firmansyah M. 2013. Analisa tataniaga biji kakao di Kecamatan Dagangan, Kare, dan Gemarang, Kabupaten Madiun [skripsi]. Bogor (ID): Institut Pertanian Bogor.

Kementrian Pertanian. 2014, Statistik Makro Sektor Pertanian 2014. Jakarta : Kementrian Pertanian

Kohl and Uhl. 2002. Marketing of Agricultural Products. Ninth Edition. Prentice Hall, New Jersey.

Limbong, W.H dan P. Sitorus. 1985. Pengantar Tataniaga Pertanian. Program Studi Manajer Koperasi Unit Desa (KUD). Bogor: Fakultas Politeknik Pertanian. IPB

Mubyarto. 1980. Pengantar Ekonomi Pertanian. LP3ES, Jakarta

Pahan, Iyun. 2011. Panduan Lengkap Kelapa Sawit Manajemen Agribisnis dari Hulu hingga Hilir. Jakarta: Penebar Swadaya.

Siregar M.A. 2012. Analisis sistem tataniaga tandan buah kelapa sawit (studi kasus Desa Perkebunan Berangir, Kecamatan
Na IX-X, Kabupaten Labuhan Batu Utara, Sumatera Utara) [skripsi]. Bogor (ID): Institut Pertanian Bogor.

Vinifera N. 2006. Analisis tataniaga komoditi kelapa kopyor (studi kasus di Desa Ngagel, Kecamatan Dukuhseti, Kabupaten Pati, Provinsi Jawa Tengah) [skripsi]. Bogor (ID): Institut Pertanian Bogor. 